\title{
Equilibrium Signal and Purchase Decision in China's IPO Net Roadshow: A Dynamic Game Approach
}

\author{
Yi Zhao and Dong Li \\ School of Management, Harbin Institute of Technology, Harbin 150001, China \\ Correspondence should be addressed to Yi Zhao; 12b910045@hit.edu.cn \\ Received 4 November 2015; Revised 15 March 2016; Accepted 5 April 2016 \\ Academic Editor: Binggen Zhang
}

Copyright ( 2016 Y. Zhao and D. Li. This is an open access article distributed under the Creative Commons Attribution License, which permits unrestricted use, distribution, and reproduction in any medium, provided the original work is properly cited.

\begin{abstract}
The net roadshow has been dominant in China's IPO (initial public offerings) roadshow structure. Considering the dynamic game with incomplete information between the issuer and investor during China's IPO net roadshow, the quality of the letter of intent is presented as a discrete signal in this paper in accordance with China's IPO net roadshow characteristics. A signaling game model is established to conclude the issuer's equilibrium signal and the investor's purchase action. The issuer disguised a letter of intent to uplift its quality if the disguising cost per share stands below the bidding spread. If the investor judges the letter of intent as highquality, the basis of purchase is that the opportunity cost per share is less than the expectation on the intrinsic value of the IPO stock. Otherwise the investor rejects purchasing on the condition that the opportunity cost outnumbers the valuation of intrinsic value. In conclusion, there exist unique separating equilibrium and pooling equilibrium as a perfect Bayesian Nash equilibrium, and the existence and uniqueness of their equilibrium domains have been verified by numerical simulation. Finally, the comprehensive empirical studies have validated only one separating and pooling equilibrium existing in China's real-world IPO market.
\end{abstract}

\section{Introduction and Literature Review}

The world's exclusive magazine Investor Relations Magazine, which focuses on relationship management between companies and investors, disclosed that $91 \%$ of 1,146 investor relations professionals consider the roadshow as the most valuable investor activity in a 2014 survey, sponsored by the Bank of America Merrill Lynch (BofAML), on enterprises of all sizes throughout the world [1]. Accordingly, classified statistics have been conducted on China's latest IPO roadshows (January 2014-June 2015) in this paper, in which we discover that, in all types of roadshows, $96.85 \%$ of IPO involve a net roadshow, and $80.76 \%$ apply a net roadshow as their unique method. Moreover, all of the IPO roadshows in China's A share market from late July 2014 to late June 2015 (the end of the latest IPO) have selected the net roadshow. Therefore, it can be indicated that the net roadshow has played a dominant role in China's IPO roadshow. Quantity and structure of various types of roadshows are illustrated in Figures 1 and 2.
The chronology of China's IPO roadshow is described as follows. The issuer first presents the letter of intent to investors, and then both the issuer and the investor interact on questions asked by the investor. As a result, a communication mode of persuasive two-way asymmetry arises in accordance with "the third mode" of investor relationship management (IRM) raised by Clarke and Murray [2].

Single function is the core characteristic of China's IPO roadshow compared with the USA, which is the origin of the roadshow. Generally, single function only serves marketing but not book-building [3-5]. Additionally, the information the issuer shows merely covers the letter of intent. The China Securities Regulatory Commission (CSRC) has particularly strengthened supervision on roadshows and ruled that issuing must be suspended once other information about the issuer is not in the disclosed letter of intent. The content of the letter of intent is almost the same as the prospectus, except that the latter includes more information acquired through book-building, such as offering price and price earnings ratios. Thus, China's IPO roadshow has become a process 


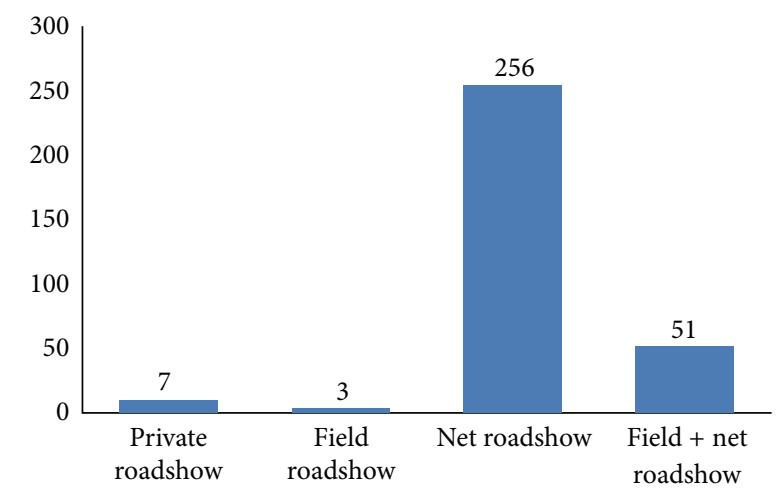

Figure 1: IPO roadshow type and its quantity in China's A share market. Data source: Wind.

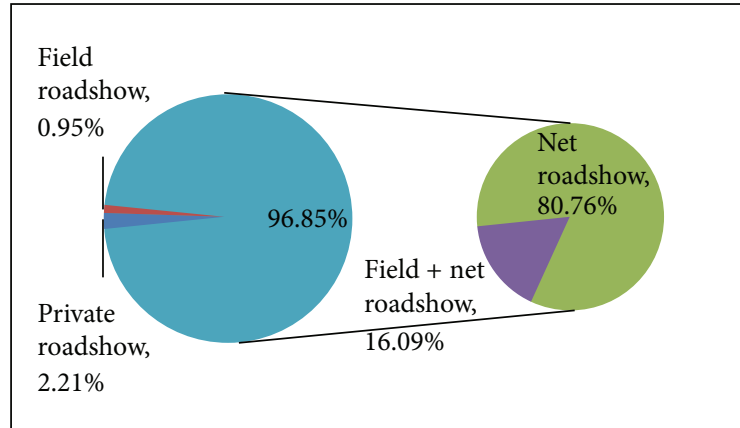

FIGURE 2: IPO roadshow structure in China's A share market. Data source: Wind.

of information disclosure on the letter of intent. According to the available literature, compulsive information disclosure results in lower estimates on the intrinsic value of new issues [6], while voluntary information disclosure helps the investor estimate the dispersion of secondary market values [7]. Based on a textual analysis of IPO prospectuses, the latest research has also proven that there is an influence of prospectus conservatism in regard to IPO pricing and proceeds [8]. Therefore, it can be concluded that, in China's IPO roadshow, the quality of the letter of intent directly affects investors' bids.

Net roadshows are featured as fair, real-time, interactive, open, efficient, low cost, and repeatable [9]. However, there still exist possibilities of false statements and leakage on the issuer information disclosure [10], because information presented in a net roadshow is only limited to the letter of intent. On one hand, the issuer has the motivation and condition of window dressing the letter of intent to attract investment on new issues; on the other hand, the investor fails to acquire information except for the letter of intent during the net roadshow and must then make a determination based on incomplete information. In essence, information disclosure of China's IPO net roadshow is a dynamic game with incomplete information between the issuer and the investor.

Literature on the relationship between the issuer and the investor can be mainly classified into two categories: (1) information asymmetry between the issuer and the investor in the perspective of accounting earnings and (2) approaches of the issuer attracting participation in the IPO in the aspect of signal revelation.

(I) As to information asymmetry between the issuer and the investor, Allen and Faulhaber have proven its existence in 1989 from the perspective of accounting earnings [11]. Recent studies have confirmed lowering the cost of capital by managing the information asymmetry between the issuer and investor (Fleischer (2006)) and have set forth a specific method of alleviating the information asymmetry between the issuer and the investor, that is, pre-IPO earnings conservation $[12,13]$. However, tremendously valuable information is excluded from traditional accounting systems due to an imperfect institutional environment in China that further exacerbates information asymmetry [14]. As a result, we insist that because this study only considered accounting earnings, it fails to eliminate the issuer's motivation of conserving private information on new issues in China's IPO market. Therefore, it is not appropriate for explaining and resolving China's realities.

(II) With regard to how the issuer attracts the investor's purchase in IPO, developing Miller's (1977) theory, Ljungqvist et al. (2006), Cook et al. (2006), and Derrien (2005) have verified that the issuer and regular customers of investment bankers benefit from noise traders in the market [15-18]. Therefore, investment bankers have an incentive to dress the IPO to attract noise traders into the IPO market. It is generally recognized in the existing literature that information of IPO value should be delivered to the investor via a signal to purchase new issue. For instance, the underwriter retention rate indicates the value of listed companies [19] and the timing of the IPO signals the quality of investment prospects to outside investors [20]. Birch (2014) discovers that the content of the signal determines not only the actual information but also the information possibly carried in the separating equilibrium of sequent evolution dynamics [21]. As a result, the quality of the letter of intent relies on both the information disclosed during the net roadshow and the information revealed by IPO stocks price evolution after the roadshow. That is to say, some determination problems during a net roadshow cannot be resolved until information feedback after the roadshow.

In other words, the above-mentioned studies involve a relationship between the issuer and the investor in IPO but have not deepened into the roadshow stage, while existing literature on IPO roadshows mostly overviews different markets. As Guanglei states preroadshows and management roadshows in the IPO of $\mathrm{H}$ share market [22], Kerins et al. describe a major feature of Japan's hybrid auction system as having no roadshow [23]. There merely exists the theoretical achievement of the roadshow stage at present. 
The remainder of this paper is organized as follows. China's IPO roadshow characteristics are theoretically studied as a combination of game actions among participants in the roadshow. First and foremost, we focus on characteristics of China's IPO net roadshow and then systematically analyze the equilibrium signal of the issuer attracting the purchase and the basis of the investor's purchase decision in the net roadshow. More importantly, contrasting with the abovementioned signals, we attempt to present a new signal generated by the core characteristic of China's IPO net roadshow and the quality of the letter of intent and establish a signaling game model in the net roadshow of China's A share market to discover an equilibrium solution and its conditions for existence. This study, as an extension of "the third mode" of the IRM theory presented by Clarke and Murray in the field of IPO, contributes to explaining some anomalies in China's IPO market, assisting the issuer to choose an equilibrium signal to spark the purchase of a new issue, providing the basis for the investor's purchase determination, enhancing participants' achievements in the roadshow and improving their decision efficiency.

\section{Research Design}

Based on the above literature review, we consider a dynamic game with incomplete information between the issuer and the investor in the process of China's IPO net roadshow. Furthermore, the dynamic game holds a fundamental feature of signaling game. There are two types of players with one single signal releaser and one single signal receiver who holds incomplete information from the signal releaser. Therefore, we build a signaling game model of the issuer and the investor in which the issuer is the signal releaser and the investor is the signal receiver.

2.1. Signal. We adopt the quality of the letter of intent to signal the investment prospects of a new issue to each investor. Moreover, the quality of the letter of intent can be measured by the investor's bid for three reasons.

First and foremost, the information China's IPO net roadshow delivers has only been confined to the letter of intent. Thus, the quality of the letter of intent becomes a symbol of information disclosed in China's IPO net roadshow.

More importantly, because of the one-way information introduction function in China's IPO net roadshow and the frequency in which window dressing of the letter of intent occurs, the information disclosed in China's IPO net roadshow cannot sufficiently reflect the real quality of the letter of intent.

Additionally, the investor also needs to aggregate various related information and combine it with his own investment experience. Then, the quality of the letter of intent can be confirmed by the investor's bid. Therefore, the investor's bid we choose to measure the quality of the letter of intent is more scientific than some points disclosed in the net roadshow.

2.2. Issuer. Throughout the entire process of IPO, players include three types: the company to be listed, the investor, the underwriter, and other IPO intermediaries including the accounting firm and the law firm. However, the company to be listed and the IPO intermediaries can be assembled as a team for offerings, because they have common interests in the stage of the net roadshow. Thus, we define the issuer as the team and explain it using the three aspects of theory, practice, and literature. A company to be listed expects maximizing financing volume; that is,

$$
\max F(p, m)=p \times m,
$$

where $F$ is the financing volume, $p$ is the offering price, and $m$ is the issuing volume of IPO stocks. IPO intermediaries maximize profits on the premise of insuring IPO success; that is,

$$
\max G(k, q)=k \times q,
$$

where $G$ is the sponsor and underwriting fee, $k$ is the rate of the fee and $k \in(0,1)$, and $q$ is the underwriting amount.

Statistics show that 317 new issues are issued in China's latest IPO (January 2014-June 2015), and all stocks are sold by underwriting, except one (stock code: 002714) sold by commission sale (data source: CCER Economic and Financial Database). Thus, we assume that all IPO stocks could be sold; that is,

$$
q=F=p \times m,
$$

where $m$ has been determined before the roadshow.

Both the company to be listed and the IPO intermediaries expect that as many as investors can participate in book building, which avoids issue suspension aroused by the insufficiency of valid bidders. Theoretically speaking, driven by common interests, the company to be listed and the IPO intermediaries will form an interest community during the roadshow stage.

In practice, the IPO intermediaries are responsible for the related events of the entire roadshow, such as interviewing and organizing investors to participate in the net roadshow, auditing financial report, writing and releasing the letter of intent, and helping the company to be listed answer questions offered by investors, and so forth. As a consequence, we can see the coherence in interests of the community.

In addition, Haixing et al. (2011) have explored the fact that the underwriter and other IPO intermediaries' opportunism behaviors result in the convergence of interests from the company to be listed and the underwriter [24]. Also, Shancun et al. (2013) have verified that the company to be listed and the underwriter should be considered as an interests community [25]. We define the community of the company to be listed and the IPO intermediaries including the underwriter, the accounting firm, and the law firm as the issuer in the roadshow stage.

2.3. Fundamental Hypothesis and Parameters. The theoretical mathematical model is established to analyze the net roadshow signaling game system, which consists of one single risk-neutral issuer and one single risk-neutral investor in a single period [26]. The issuer first emits a favorable signal 


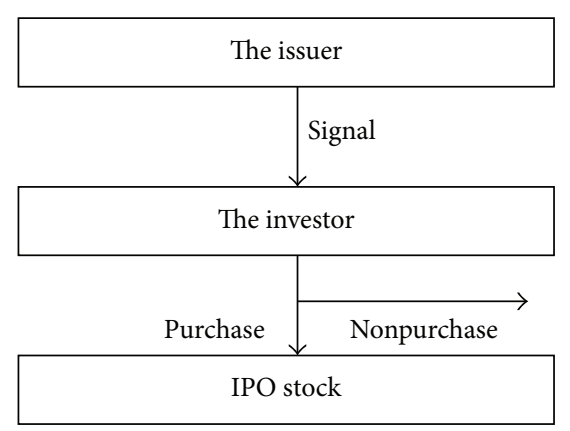

FIgURE 3: The process of signal revelation of China's IPO net roadshow.

(i.e., the letter of intent) to attract investors to purchase a new issue. Based on information received from the signal and the investors' own investigation and experience, they can infer the investment value of IPO stocks and decide whether or not to purchase IPO stocks, in order to maximize their own expected utility. The issuer is the game leader, and the investor is the game follower [27]. The process of signal revelation of China's IPO net roadshow is described in Figure 3.

\section{The Fundamental Hypothesis}

(H1) On the condition that the letter of intent disclosed in the net roadshow convinces the investor of the investment value of IPO stocks, the investor will purchase IPO stocks and pay his or her opportunity cost [28].

(H2) On the condition that the letter of intent disclosed in the net roadshow does not convince the investor of the investment value of IPO stocks, the investor will not purchase new issue and will pay no opportunity cost.

(H3) The issuer must pay a signaling cost only if the roadshow occurs.

(H4) Both the issuer and the investor rationally maximize their own interests in light of the given conditions.

(H5) A lower intrinsic value of IPO stocks deserves a higher cost for disclosing the letter of intent with equal quality $[29,30]$.

(H6) The game between the issuer and the investor belongs to noncooperative game based on the rationality of individual behaviors, which indicates that it is impossible for both players to seek maximal common profits through collusion.

The Main Parameters. $V_{i}$ is the intrinsic value of IPO stocks, where $i \in\{L, H\} . V_{h}$ indicates a high intrinsic value while $V_{l}$ indicates a low intrinsic value. It is apparent that $V_{h}>V_{l}>0$. The type set of IPO stocks is formulated as $V=\left\{V_{h}, V_{l}\right\}$. The investor can only discern a signal from the issuer, that is, the quality of the letter of intent, and then make an evaluation on the intrinsic value of IPO stocks.

$\theta$ is the investor's belief on the high intrinsic value of IPO stocks before the roadshow, which is noted as $P\left(V_{h}\right)=\theta$ and regarded as common knowledge. Therefore, $P\left(V_{l}\right)=1-\theta$, where $\theta \in[0,1]$.

$S_{j}$ is the investor's judgment on the quality of the letter of intent according to information disclosed through the net roadshow as well as the investor's own survey and experience. In other words, $S_{j}$ could be measured by the investor's bid for purchasing IPO stocks, where $j \in\{L, H\}$. When the investor considers the letter of intent as high-quality, the bid is marked as $S_{h}$. Otherwise, it is noted as $S_{l}$. It is obvious that $S_{h}>S_{l}>0$. Hence, we measure the quality of the letter of intent by $S_{j}$, with a signal set of $S=\left\{S_{h}, S_{l}\right\}$.

The investor will purchase IPO stocks when $S_{h}-V_{h}>0$ or $S_{l}-V_{l}>0$. Additionally, the investor is willing to purchase IPO stocks with a higher intrinsic value; that is, $S_{h}-V_{h}>S_{l}-$ $V_{l}>0$. Clearly, $V_{l}-S_{h}<0$, which fulfills China's IPO market that the bid mostly surpasses IPO's intrinsic value once the investor decides to purchase IPO stocks and that the investor seems to prefer to purchase IPO stocks with high intrinsic value [31].

$A_{k}$ is the issuer's action, where $k \in\{1,2\} . A_{1}$ refers to purchase while $A_{2}$ indicates nonpurchase. The set of the investor's actions is formulated as $A=\left\{A_{1}, A_{2}\right\}$. As $S_{j}$ refers to the investor's valuation on the quality of the letter of intent, the posterior probability $P\left(V_{i} \mid S_{j}\right)$ can be calculated based on Bayes' rule; then the investor will decide whether to purchase IPO stocks; that is,

$$
P\left(V_{i} \mid S_{j}\right)=\frac{p\left(V_{i}\right) \times p\left(S_{j} \mid V_{i}\right)}{\sum_{i \in\{h, l\}} p\left(V_{i}\right) \times p\left(S_{j} \mid V_{i}\right)} .
$$

$Y_{i j}$ is the signaling cost per share of IPO stocks. This is the function on purchase price and the intrinsic value of IPO stocks as $Y_{i j}=Y\left(S_{j}, V_{i}\right)$, where $i \in\{L, H\}$ and is featured as follows:

(1) The signaling cost of the net roadshow is $Y_{i j}>0$.

(2) $\partial Y(S, V) / \partial S>0$ : signaling cost varies in the same direction with the quality of the letter of intent.

(3) $Y\left(S_{j}, V_{h}\right)<Y\left(S_{j}, V_{l}\right)$ : the issuer who holds lower intrinsic value stocks needs a higher signaling cost for equal quality of the letter of intent disclosed in the net roadshow.

$C_{i}$ is the purchase opportunity cost per share, and $C_{i}=$ $C\left(V_{i}\right)$, where $i \in\{L, H\}$. When nonpurchase is conducted, 


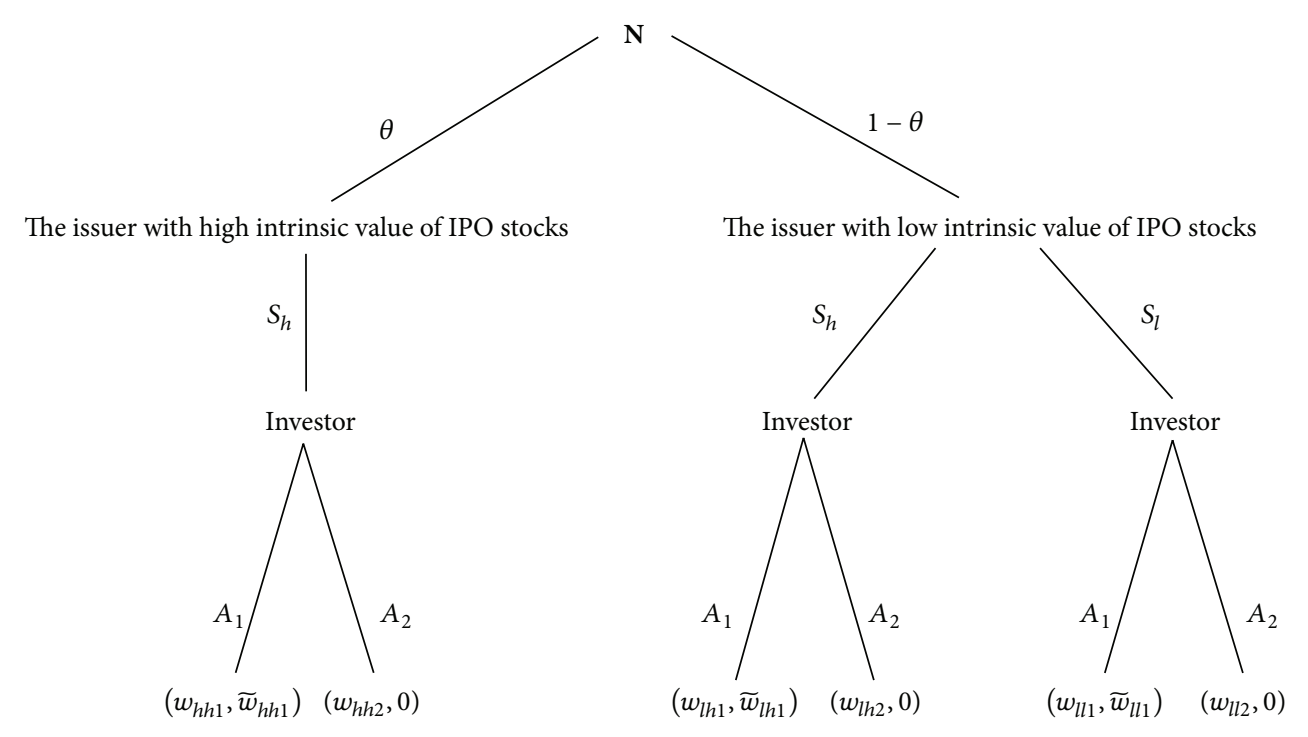

FIgURE 4: Extensive form of the signaling game of China's IPO net roadshow.

$C_{i}=0$; if the investor chooses purchase, $C_{i}>0$, where $C_{h}=$ $C\left(V_{h}\right), C_{l}=C\left(V_{l}\right)$, and $C_{h}>C_{l}>0$. According to the costeffective principle, if $V_{i}>C_{i}$ where $i \in\{L, H\}$, the investor will take the purchase into consideration.

$w_{i j k}$ and $\widetilde{w}_{i j k}$ are net profits acquired by the issuer and the investor, respectively, in the signaling game of the net roadshow. As both depend on $V_{i}, S_{j}$, and $A_{k}$, the net profits of the issuer and investor can be expressed as $w_{i j k}=$ $w\left(V_{i}, S_{j}, A_{k}\right)$ and $\widetilde{w}_{i j k}=\widetilde{w}\left(V_{i}, S_{j}, A_{k}\right)$, respectively.

$U_{i j k}$ is the investor's expected utility in the signaling game of the roadshow; that is,

$$
U_{i j k}=\sum_{i \in\{h, l\}} P\left(V_{i} \mid S_{j}\right) w\left(V_{i}, S_{j}, A_{k}\right) .
$$

\subsection{The Process Analysis of the Signaling Game of \\ China's IPO Net Roadshow}

The First Stage. Nature $(N)$ determines the type of IPO stocks by means of Harsanyi transformation. The issuer knows the type of IPO stocks, whereas the investor does not. The investor holds prior probability on the high intrinsic value of IPO stocks before the roadshow; that is, $\theta=P\left(V_{h}\right)$, and then $P\left(V_{l}\right)=1-\theta$, where $\theta \in[0,1]$.

The Second Stage. On the premise of knowing the type of IPO stocks, the issuer chooses to disclose the signal $S_{h}$ or $S_{l}$. Because the issuer can predict the action of the investor according to a given signal, he will choose equilibrium signal to maximize his own payoffs.

The Last Stage. The investor receives the signal released by the issuer in the roadshow and then modifies prior probability $\theta$ and concludes the posterior probability $P\left(V_{i} \mid S_{j}\right)(i, j \in$ $\{L, H\})$, satisfying Bayes' rule. Accordingly, the investor will make a decision through which the investor's expected utility will be maximized.

On the basis of (H4), the issuer who holds the high intrinsic value of IPO stocks does not reveal a letter of intent with low quality. Hence, the extensive form of the signaling game of China's IPO net roadshow is described in Figure 4.

The extensive form in Figure 4 shows that the issuer can choose two types of signal strategies: $\left(S_{h}, S_{h}\right)$ and $\left(S_{h}, S_{l}\right)$. $\left(S_{x}, S_{y}\right)$ mean that the issuer with $V_{h}$ IPO stocks should reveal the letter of intent of which the quality is measured by $S_{x}$, where $S_{x} \equiv S_{h}$.

Correspondingly, the issuer with $V_{l}$ IPO stocks should disclose the letter of intent of which the quality is measured by $S_{y}$. For example, $\left(S_{h}, S_{h}\right)$ means that both issuers with $V_{h}$ and $V_{l}$ IPO stocks disclose the letter of intent in which the quality is measured by $S_{h}$.

The investor has four action strategies based on the signal released by the issuer: $\left(A_{1}, A_{1}\right),\left(A_{2}, A_{2}\right),\left(A_{1}, A_{2}\right)$, and $\left(A_{2}, A_{1}\right) .\left(A_{x}, A_{y}\right)$ indicates that action $A_{x}$ will be conducted by the investor if the quality of the letter of intent is considered as $S_{h}$ and action $A_{y}$ will be conducted by the investor if the quality of the letter of intent is considered as $S_{l}$. Clearly, $\left(A_{2}, A_{1}\right)$ appears to contradict actual rational behavior, as is not consistent with (H3). Thus, we study the former three action strategies.

2.5. Payoffs Analysis. Payoffs of the signaling game of China's IPO net roadshow are illustrated as in Figure 5, and the payoffs matrix is shown in Table 1, where the former expression is the issuer's net profit and the latter is the investor's.

\section{Signaling Game Model of China's IPO Net Roadshow}

3.1. The Investor's Purchase Decision Problem. The investor first concludes posterior probability in the condition of one 
TABLE 1: Payoffs matrix of the signaling game of China’s IPO net roadshow.

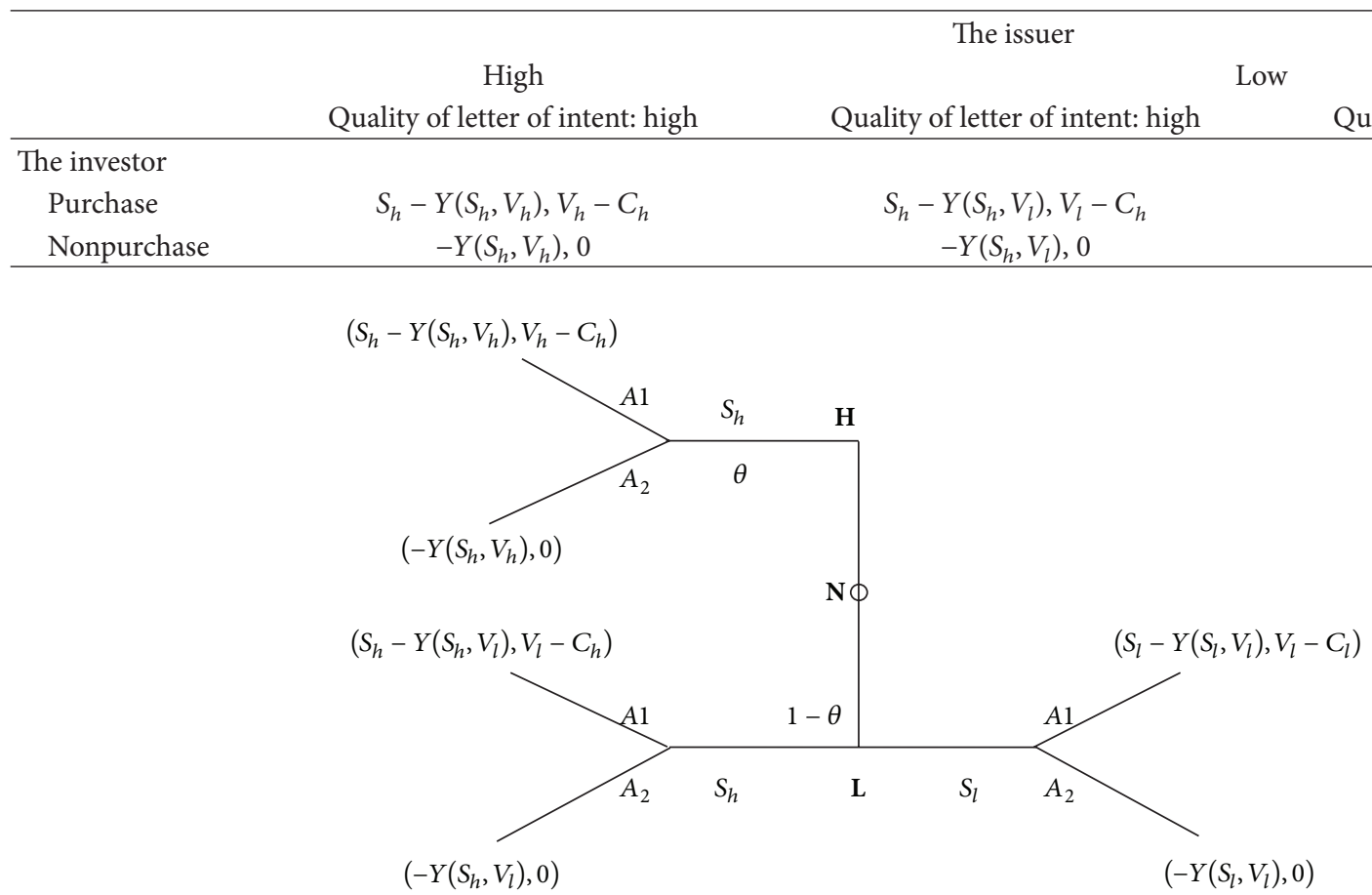

FIGURE 5: Extensive form within payoffs of signaling game of China's IPO net roadshow.

arbitrary signal by Bayes' rule. Then, the investor's action decision depends on whether to purchase IPO stocks to maximize his own expected utility. If satisfying (6), the investor's action is only an optimal action decision, that is, $A^{*}\left(S_{j}\right)$.

$$
\max _{A_{k} \in A} \sum_{i \in\{h, l\}} P\left(V_{i} \mid S_{j}\right) w\left(V_{i}, S_{j}, A_{k}\right)
$$

(1) The Investor's Expected Utility Analysis If the Letter of Intent Is of High-Quality $\left(S_{h}\right)$. The investor attributes the quality of the letter of intent to $S_{h}$, but the intrinsic value of IPO stocks might be $V_{h}$ or $V_{l}$. If the investor chooses purchase $\left(A_{1}\right)$, his expected utility will be formulated as follows:

$$
\begin{aligned}
U_{i h 1} & =\sum_{i \in\{h, l\}} p\left(V_{i} \mid S_{h}\right) w\left(V_{i}, S_{h}, A_{1}\right) \\
& =\frac{\theta\left(V_{h}-C_{h}\right)+(1-\theta) p\left(S_{h} \mid V_{l}\right)\left(V_{l}-C_{h}\right)}{\theta \times 1+(1-\theta) p\left(S_{h} \mid V_{l}\right)},
\end{aligned}
$$

where

$$
\begin{aligned}
p\left(V_{h} \mid S_{h}\right) & =\frac{p\left(V_{h}\right) \times p\left(S_{h} \mid V_{h}\right)}{p\left(S_{h} \mid V_{h}\right) p\left(V_{h}\right)+p\left(S_{h} \mid V_{l}\right) p\left(V_{l}\right)} \\
& =\frac{\theta \times 1}{\theta \times 1+(1-\theta) p\left(S_{h} \mid V_{l}\right)},
\end{aligned}
$$

$$
\begin{aligned}
p\left(V_{l} \mid S_{h}\right) & =\frac{p\left(V_{l}\right) \times p\left(S_{h} \mid V_{l}\right)}{p\left(S_{h} \mid V_{h}\right) p\left(V_{h}\right)+p\left(S_{h} \mid V_{l}\right) p\left(V_{l}\right)} \\
& =\frac{(1-\theta) \times p\left(S_{h} \mid V_{l}\right)}{\theta \times 1+(1-\theta) p\left(S_{h} \mid V_{l}\right)} .
\end{aligned}
$$

Vice versa, $U_{i h 2}=0$.

It is clear that if $U_{i h 1}>U_{i h 2}$, that is, $0<p\left(S_{h} \mid V_{l}\right)<$ $(\theta /(1-\theta)) \times\left(\left(V_{h}-C_{h}\right) /\left(C_{h}-V_{l}\right)\right)$, then $A^{*}\left(S_{h}\right)=A_{1}$.

Theorem 1. When the investor attributes the quality of the letter of intent to $S_{h}$, if $0<p\left(S_{h} \mid V_{l}\right)<(\theta /(1-\theta)) \times$ $\left(\left(V_{h}-C_{h}\right) /\left(C_{h}-V_{l}\right)\right)$, the investor's optimal action decision is purchase; that is, $A^{*}\left(S_{h}\right)=A_{1}$.

Corollary 2. When the investor attributes the quality of the letter of intent to $S_{h}$, if and only if $C_{h}<E V$, that is to say, if the opportunity cost per share for purchase is less than the expectation on intrinsic value, then $0<p\left(S_{h} \mid V_{l}\right)<1<$ $(\theta /(1-\theta)) \times\left(\left(V_{h}-C_{h}\right) /\left(C_{h}-V_{l}\right)\right)$; therefore, all potential investors have no alternative but to purchase a new issue.

Exact intrinsic value is the issuer's private information, while the expectation for intrinsic value can be easily estimated by the investor. As a result, Corollary 2 is more suitable than Theorem 1 for the investor's purchase decision.

(2) The Investor's Expected Utility Analysis If the Letter of Intent Is of Low Quality $\left(S_{l}\right)$. If the investor attributes the quality of the letter of intent to $S_{l}$, then the intrinsic value of IPO stocks 
must be $V_{l}$. If the investor chooses purchase $\left(A_{1}\right)$, then his expected utility will be formulated as $U_{l l 1}=V_{l}-C_{l}$, and vice versa $U_{l l 2}=0$.

Theorem 3. When the investor attributes the quality of letter of intent to $S_{l}$, if $V_{l}>C_{l}$, then $A^{*}\left(S_{l}\right)=A_{1}$. That is to say, the investor will reject purchasing IPO stocks; once the investors consider the letter of intent as low quality (the opportunity cost per share $>$ the intrinsic valuation of IPO stocks), they will reject purchasing IPO stocks.

3.2. The Issuer's Equilibrium Signal Problem. The goal of the net roadshow is to appeal to investors. Thus, signaling plays a crucial role in IPO. On the basis of Sections 2.4 and 2.5, we consider the equilibrium signal to be what attracts the investor to purchase IPO stocks. Therefore, the equilibrium signal of the issuer with $V_{i}$ IPO stocks is the solution of the optimization problem as below:

$$
\max _{S_{j} \in S} w\left(V_{i}, S_{j}, A_{1}\right)
$$

(1) The Payoffs Analysis of the Issuer with $V_{h}$ IPO Stocks in the Net Roadshow. The issuer with $V_{h}$ IPO stocks only discloses the letter of intent with high-quality $\left(S_{h}\right)$.

(2) The Payoffs Analysis of the Issuer with $V_{l}$ IPO Stocks in the Net Roadshow. The issuer with $V_{l}$ IPO stocks might reveal the letter of intent with high-quality $\left(S_{h}\right)$ or low quality $\left(S_{l}\right)$ and $S_{h}>S_{l}>0$. If the issuer with $V_{l}$ IPO stocks reveals the letter of intent with high-quality $\left(S_{h}\right)$, then $w\left(V_{l}, S_{h}, A_{1}\right)=$ $S_{h}-Y\left(S_{h}, V_{l}\right)$; vice versa $w\left(V_{l}, S_{l}, A_{1}\right)=S_{l}-Y\left(S_{l}, V_{l}\right)$. By the fundamental hypothesis $\partial Y(S, V) / \partial S>0$; that is, $Y\left(S_{h}, V_{l}\right)-$ $Y\left(S_{l}, V_{l}\right)>0$; let $y=Y\left(S_{h}, V_{l}\right)-Y\left(S_{l}, V_{l}\right)>0$ indicate the additional disguising cost per share that the issuer with $V_{l}$ IPO stocks additionally pays for window dressing the letter of intent so that

$$
\begin{aligned}
\Delta & =S_{h}-Y\left(S_{h}, V_{l}\right)-\left[S_{l}-Y\left(S_{l}, V_{l}\right)\right] \\
& =S_{h}-S_{l}+Y\left(S_{l}, V_{l}\right)-Y\left(S_{h}, V_{l}\right)=S_{h}-S_{l}-y .
\end{aligned}
$$

Theorem 4. The issuer with $V_{l}$ IPO stocks will choose to disclose the type of letter of intent, if the following conditions are satisfied:

(1) $\Delta>0 \Leftrightarrow S_{h}-S_{l}>y>0$ : the high-quality letter of intent will be chosen to be revealed.

(2) $\Delta<0 \Leftrightarrow y>S_{h}-S_{l}>0$ : the low-quality letter of intent will be chosen to be revealed, where $S_{h}-S_{l}$ is the investor's bidding spread after the net roadshow.

\section{The Perfect Bayesian Nash Equilibrium Solution}

A perfect Bayesian Nash equilibrium is a strategy combination that continues to be an optimal strategy for each player and the updated beliefs of the players, when the beliefs are updated using Bayes' rule. The signaling game has three types of Perfect Bayesian Nash equilibrium solutions: separating equilibrium, pooling equilibrium, and semiseparating equilibrium [32]. The issuer has only two types of signals and two types of IPO stocks. A specific type of issuer can only emit one type of signal in the net roadshow but cannot reveal two types of signals simultaneously. As a result, the semiseparating equilibrium does not exist. We concentrate only on the separating equilibrium and pooling equilibrium.

4.1. Pooling Equilibrium. Single pure common strategy combination $\left(S_{h}, S_{h}\right)$ exists in the issuer's signal spaces, while the investor's action spaces have two pure common strategy combinations: $\left(A_{1}, A_{1}\right)$ and $\left(A_{2}, A_{2}\right)$; thus, there might be two types of pooling equilibrium: $\left\{\left(S_{h}, S_{h}\right),\left(A_{1}, A_{1}\right)\right\}$ and $\left\{\left(S_{h}, S_{h}\right),\left(A_{2}, A_{2}\right)\right\}$.

Theorem 5. $\left\{\left(S_{h}, S_{h}\right),\left(A_{2}, A_{2}\right)\right\}$ is not a perfect Bayesian Nash equilibrium.

Proof. Suppose that both types of IPO stock issuers disclose a high-quality letter of intent; that is, $S\left(V_{h}\right)=S\left(V_{l}\right)=S_{h}$. Thus, for $\forall V_{i}$, where $i \in\{l, h\}$, the investor's expected utility $U\left(V_{l}, S_{h}, A_{2}\right)=U\left(V_{h}, S_{h}, A_{2}\right)=0$.

Given the investor's action strategy combination $\left(A_{2}, A_{2}\right)$, we know that the issuer with $V_{h}$ IPO stocks only emits the signal $S_{h}$. Thus, we only need to verify the following: if $w\left(V_{l}, S_{h}, A_{2}\right)>w\left(V_{l}, S_{l}, A_{2}\right)$, then $\left\{\left(S_{h}, S_{h}\right),\left(A_{2}, A_{2}\right)\right\}$ is the equilibrium solution. However, Table 1 notes that $w\left(V_{l}, S_{h}, A_{2}\right)=-Y\left(S_{h}, V_{l}\right), w\left(V_{l}, S_{l}, A_{2}\right)=-Y\left(S_{l}, V_{l}\right)$, if $-Y\left(S_{h}, V_{l}\right)>-Y\left(S_{l}, V_{l}\right)$, and this finding is concluded to be in contradiction with the hypothesis $\partial Y / \partial S>0$.

Therefore, $\left\{\left(S_{h}, S_{h}\right),\left(A_{2}, A_{2}\right)\right\}$ is not a perfect Bayesian Nash equilibrium.

Theorem 6. There exists a unique pooling equilibrium $\left\{\left(S_{h}, S_{h}\right),\left(A_{1}, A_{1}\right), p\left(V_{l} \mid S_{l}\right)=1, p\left(V_{h} \mid S_{l}\right)=0\right\}$ as a perfect Bayesian Nash equilibrium, if, for each player, we have

(1) $C_{h}<E V$, while discerning the letter of intent disclosed in the net roadshow as high-quality and the investor's purchase opportunity cost per share is less than the expectation on IPO stocks' intrinsic value;

(2) $0<y<S_{h}-S_{l}$, while the issuer's additional disguising cost per share on the letter of intent is less than the investor's bidding spread.

Proof. Suppose that both types of IPO stock issuers disclose a high-quality letter of intent; that is, $S\left(V_{h}\right)=S\left(V_{l}\right)=S_{h}$. Based on Corollary 2, if $C_{h}<\mathrm{EV}$, then $A^{*}\left(S_{h}\right)=A_{1}$. Given the investor's action strategy combination $\left(A_{1}, A_{1}\right), p\left(S_{h} \mid V_{h}\right)=$ 1 and $w\left(V_{h}, S_{h}, A_{1}\right)=S_{h}-Y\left(S_{h}, V_{h}\right)$ are known, so we only need to compare $w\left(V_{l}, S_{h}, A_{1}\right)$ with $w\left(V_{l}, S_{l}, A_{1}\right)$.

By (10), we have that if $0<y<S_{h}-S_{l}$, then $w\left(V_{l}, S_{h}, A_{1}\right)>$ $w\left(V_{l}, S_{l}, A_{1}\right)$. Thus, the issuer with $V_{h}$ IPO stocks will have equilibrium signal $S_{h}$ and $\left(S_{h}, S_{h}\right)$ is the equilibrium signal strategy combination.

On the basis of the above conclusions, the existence and uniqueness of the pooling equilibrium domain of the 


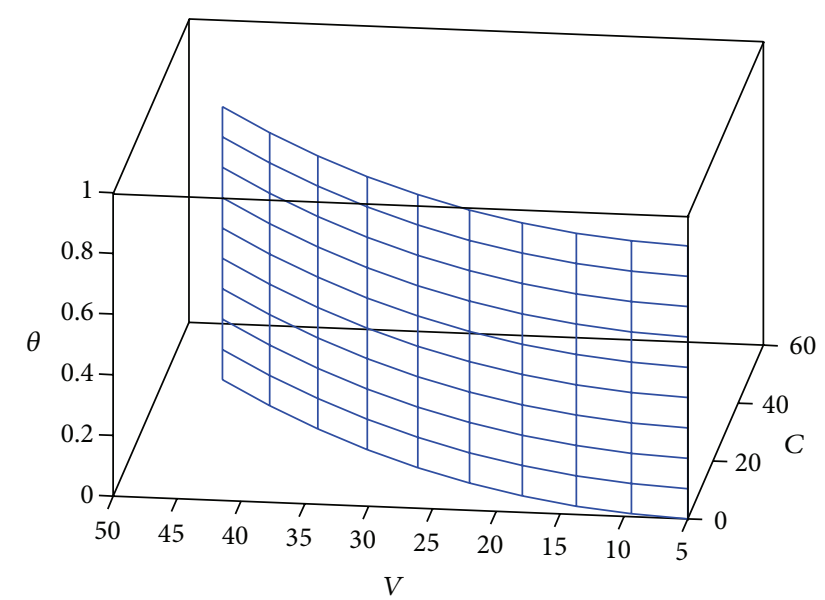

Figure 6: The variation of $C$ with $V$ and $\theta$ under the circumstance of the pooling equilibrium.

signaling game of China's IPO net roadshow are also validated by means of numerical simulation. $\theta \in[0,1]$ and $y \in$ $\left(0, S_{h}-S_{l}\right)$ are known. Approximately $90 \%$ of IPO stocks' intrinsic value in China has been distributed between 5 and 50 yuan [33]. We assume that $V \in[5,50]$ and that purchase opportunity cost per share is $C \in[0,50]$. The unique pooling equilibrium domain is illustrated in Figure 6.

The economic significance of the pooling equilibrium in China's IPO net roadshow can be listed as follows:

(1) During the net roadshow, the issuer intends to choose whether to make window dressing of the letter of intent by balancing the relationship between disguising cost per share and bidding spread. As a two-stage book-building system is adopted in China's A share IPO, the bidding spread can be obtained in the bookbuilding stage. Our conclusions can be applied in IPO of China's A share market.

(2) Because the investor can only make assessments about the intrinsic value of new issues as they are unable to be informed of the exact intrinsic value, it is easier for them to obtain the expectation of intrinsic value and utilize it to make investment decisions. When making purchase determinations on high-quality letters of intent, the investor only needs to focus on the relationship between the purchase opportunity cost per share and the expectation of its intrinsic value. As a result, conclusions drawn in the paper enable investors to enhance their decisionmaking efficiency.

\subsection{Separating Equilibrium}

Theorem 7. There exists a unique separating equilibrium $\left\{\left(S_{h}, S_{l}\right),\left(A_{1}, A_{2}\right), p\left(V_{l} \mid S_{l}\right)=1, p\left(V_{l} \mid S_{h}\right)=0\right\}$ as a perfect Bayesian Nash equilibrium, if, for each player, we have

(1) $C_{h}<E V$, while discerning the letter of intent disclosed in the net roadshow as high-quality, the investor will purchase IPO stocks if the investor's purchase opportunity cost per share is less than the expectation on the IPO stocks' intrinsic value;

(2) $C_{l}>V_{l}$, while discerning the letter of intent disclosed in the net roadshow as low quality, the investor will reject purchasing IPO stocks if the opportunity cost per share outnumbers the intrinsic value.

Proof. It is well known that the issuer has only one separating signal strategy; that is, $S\left(V_{h}\right)=S_{h}, S\left(V_{l}\right)=S_{l}$. Based on Corollary 2, while the investor discerns the letter of intent disclosed in the net roadshow as high-quality, only if $C_{h}<\mathrm{EV}$, then the investor will choose to purchase, that is, $A^{*}\left(S_{h}\right)=A_{1}$.

On the contrary, if the investor identifies the letter of intent disclosed in the net roadshow as low-quality, as $p\left(V_{l} \mid\right.$ $S_{l}$ ) $=1$ is known, then the type of IPO stocks is of low intrinsic value. Hence, for the investor, the expected utility of the purchase is $U_{i l 1}=V_{l}-C_{l}$; vice versa, $U_{i l 2}=0$. Therefore, if and only if $U_{i l 2}>U_{i l 1}$, that is, $C_{l}>V_{l}$, the investor will abandon purchase, that is, $A^{*}\left(S_{l}\right)=A_{2}$.

Given the investor's action strategy combination $\left(A_{1}, A_{2}\right)$, as $p\left(S_{h} \mid V_{h}\right)=1$ and $w\left(V_{h}, S_{h}, A_{1}\right)=S_{h}-Y\left(S_{h}, V_{h}\right)$ are known, we only need to compare $w\left(V_{l}, S_{h}, A_{2}\right)$ with $w\left(V_{l}, S_{l}, A_{2}\right)$, because $w\left(V_{l}, S_{h}, A_{2}\right)=-Y\left(S_{h}, V_{l}\right)$ and $w\left(V_{l}, S_{l}\right.$, $\left.A_{2}\right)=-Y\left(S_{l}, V_{l}\right)$ are known. It is clear that $-Y\left(S_{h}, V_{l}\right)<$ $-Y\left(S_{l}, V_{l}\right)$. Hence, $w\left(V_{l}, S_{l}, A_{2}\right)>w\left(V_{l}, S_{h}, A_{2}\right)$, and $\left(S_{h}, S_{l}\right)$ is the separating equilibrium signal strategy.

On the basis of the above conclusions, the existence and uniqueness of the separating equilibrium domain of the signaling game of China's IPO net roadshow are also validated by means of numerical simulation. We adopt the same empirical data as the pooling equilibrium, and the unique separating equilibrium domain is illustrated as in Figure 7.

To summarize, the economic significance of the separating equilibrium in China's IPO net roadshow is listed as follows:

(1) If China's IPO market remains orderly and if credible information about the letter of intent is released to the public, investors can discover the investment value of IPO stocks only by means of the letter of intent. However, the phenomenon of window dressing the letter of intent is fairly common in China's IPO market in practice. Since December 2013, supervisors carried out a series of reform measures to reduce the lottery rate of valid purchases, and further supervision on information disclosure was strengthened as well. Therefore, issuers are obliged to establish a prudent analysis on the additional cost and benefits of window dressing.

(2) Through participation in several issuers' roadshows, investors can categorize letters of intent into two types: high-quality and low quality. Regarding a highquality letter of intent, only the relationship between purchase opportunity cost per share and expectation of intrinsic value should be taken into consideration 


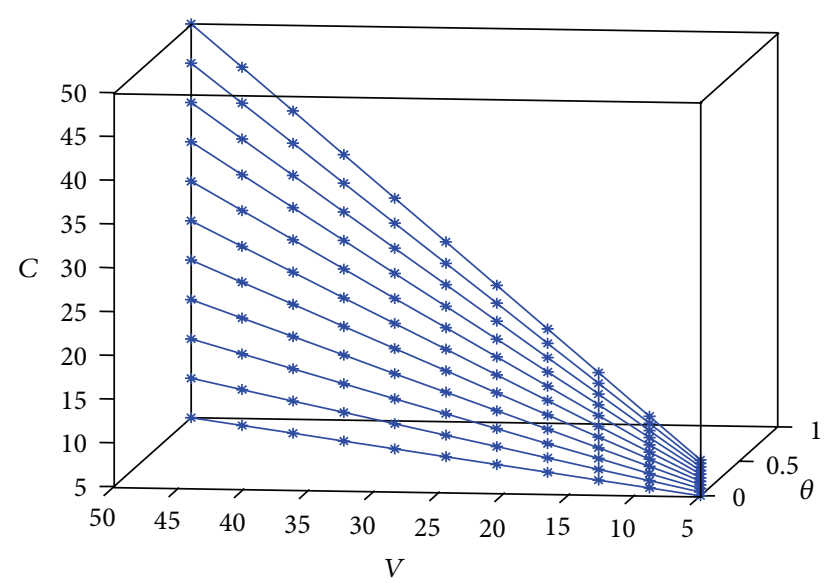

FIgURE 7: The variation of $C$ with $V$ and $\theta$ under the circumstance of the separating equilibrium.

by the investor; for a low-quality letter of intent, the investor should focus on the relationship between the purchase opportunity cost per share and the intrinsic valuation.

\section{Empirical Study}

5.1. Empirical Study on Separating Equilibrium. On the basis of theoretical proof in Section 4.2, the criterion on determining the only one separating equilibrium is the perfect Bayesian Nash equilibrium and is the comparison between the investor's opportunity cost of purchasing new issues $(C)$ and the intrinsic value of IPO stock $(V)$. Thus, the empirical study on separating equilibrium focuses on evaluating two variables above.

5.1.1. Valuation on the Intrinsic Value of the IPO Stock $(V)$. Because the information disclosed by China's IPO net roadshow remains restricted to the letter of intent, from which the parameters required by Residual Income Model (RIM) could be directly acquired, the RIM serves as the most appropriate valuation model on the intrinsic value of China's IPO stock [33]. More importantly, Chinese investors, based on information disclosed in the letter of intent, can only forecast listed companies development status within the coming $N$ years but not afterwards. Accordingly, Huangsong (2005) updated the traditional RIM to make it more suitable for China's IPO market [34]. In this paper, the intrinsic value of China's IPO stock is evaluated by methods of Huangsong (2005) and its valuation model is as follows:

$$
\begin{aligned}
V_{t} & =B V_{t}\{1 \\
& \left.+\frac{\operatorname{ROE}-\rho}{1+\rho} \sum_{i=1}^{N}\left[\frac{1+\operatorname{ROE}(1-\beta)-\rho}{1+\rho}\right]^{i-1}\right\},
\end{aligned}
$$

where $V_{t}$ is the intrinsic value of the IPO stock, $B V_{t}$ is the carrying value of net asset per share before IPO, $N$ is the predictive period of investors (year), ROE is the rate of return on common stockholders' equity, $\rho$ is the risk-free interest rate, and $\beta$ is the dividend rate.

5.1.2. Valuation on the Investor's Opportunity Cost of Purchasing New Issues (C). In China's IPO market, the process of purchasing new issues must undergo three critical dates, which include purchase date $\left(T_{0}\right)$, demand-to-offer date $\left(T_{1}\right)$, and offering date $\left(T_{2}\right)$. Investors must pay all the purchase capital for IPO stocks on $T_{0}$. The demand-to-offer results are announced on $T_{1}$; then the IPO stocks successfully purchased issues on $T_{2}$ while the capital failing to purchase new issues returns to the accounts of investors on $T_{1}+1$. Chan et al. (2009) had conducted systemic research on opportunity cost of purchasing new issues [35]. In this paper, $C$ is evaluated by methods of Chan et al. (2009) and its valuation model is as follows:

$$
\begin{aligned}
& C_{t} \\
& \quad=P_{0}\left[\prod_{i=1}^{T_{1}-T_{0}}\left(1+\frac{r_{1}}{360}\right)-(1-q)\right] \prod_{j=1}^{T_{2}-T_{1}}\left(1+\frac{r_{2}}{360}\right),
\end{aligned}
$$

where $C_{t}$ is the opportunity cost of purchasing new issues, $P_{0}$ is the offering prices of the stock, $q$ is the demand-to-offer ratio, $r_{1}$ is the risk-free interest rate during $T_{1}-T_{0}$ (annual rate), and $r_{2}$ is the risk-free interest rate during $T_{2}-T_{1}$ (annual rate).

5.1.3. Empirical Test on Separating Equilibrium: Taking the Internet Finance Stocks of China's A Share Market as the Samples. The Internet Finance, as a combination of traditional financial industry and internet concept, has emerged in China's capital market in the past two years. In a broad sense, all the financial modes with Internet concept can be covered in the field of Internet Finance [36]. Five internet financial stocks had been issued in China's A share market during January 2014-June 2015. We take them as the empirical samples. According to the 48th Article of the 28th Information Disclosure Content and Format Standards for Listed Companies (the Revised Version in 2014), the issuers should disclose the development strategies and measures in the coming three years [37]. Consequently, the predictive period is set as $N=3$, the risk-free interest rate is the annual rate of three-year national debt, and the ROE is the rate of return on common stockholders' equity for each IPO stock. The results in Table 2 are evaluated based on formula (11) and (12).

Consistent with Theorem 7, we explore that the opportunity cost of purchasing number 2 stock (Amarsoft) has surpassed the number 2 stock's intrinsic value; that is, $C_{t}>$ $V_{t}$, which falls in line with condition (2) of Theorem 7. We also find that the opportunity costs of other four stocks keep less than their own expectation on the intrinsic value, respectively, in coming three years; that is, $C_{t}<\mathrm{EV}$, conforming to condition (1) of Theorem 7. As a result, the five stocks above except Amarsoft (300380) can be purchased. In fact, among the five stocks, only Amarsoft (300380) is under investigation by China Securities Regulatory Commission 
TABLE 2: Real-world parameters and results of empirical study on separating equilibrium.

\begin{tabular}{|c|c|c|c|c|c|c|c|c|c|c|}
\hline Number & $\begin{array}{l}\text { Stock } \\
\text { name }\end{array}$ & Stock code & $T_{0}$ & $T_{1}$ & $T_{2}$ & $T_{1}-T_{0}$ (days) & $r_{1}(\%)$ & $T_{2}-T_{1}$ (days) & $r_{2}(\%)$ & $q(\%)$ \\
\hline 1 & $\begin{array}{l}\text { Kingee } \\
\text { Culture }\end{array}$ & 002721 & 2014.1.16 & 2014.1.21 & 2014.1.27 & 6 & $5.00 \%$ & 5 & $5.00 \%$ & $20.15 \%$ \\
\hline 2 & Amarsoft & 300380 & 2014.1.17 & 2014.1.22 & 2014.1.28 & 6 & $5.00 \%$ & 5 & $5.00 \%$ & $19.14 \%$ \\
\hline 3 & $\begin{array}{l}\text { Dong Yi Ri } \\
\text { Sheng }\end{array}$ & 002713 & 2014.2.11 & 2014.2.14 & 2014.2.19 & 4 & $5.00 \%$ & 4 & $5.00 \%$ & $14.31 \%$ \\
\hline 4 & $\begin{array}{c}\text { Kunlun } \\
\text { Tech }\end{array}$ & 300418 & 2015.1.13 & 2015.1.16 & 2015.1.21 & 4 & $4.92 \%$ & 4 & $4.92 \%$ & $0.21 \%$ \\
\hline 5 & Ideal & 002740 & 2015.1.14 & 2015.1.19 & 2015.1.22 & 6 & $4.92 \%$ & 2 & $4.92 \%$ & $1.00 \%$ \\
\hline$P_{0}$ (yuan) & ROE (\%) & $\rho(\%)$ & $\beta(\%)$ & $B V_{t}$ & $C_{t}$ & $V_{l}(N=1)$ & $V_{h}(N=3)$ & $\mathrm{EV}$ & \multicolumn{2}{|c|}{$C_{t}$ VS. EV $\left(\right.$ or $\left.V_{l}\right)$} \\
\hline 10.55 & $18.80 \%$ & $5.00 \%$ & $16.11 \%$ & 4.17 & 2.14 & 4.718 & 5.835 & 5.28 & \multicolumn{2}{|c|}{$C_{t}<\mathrm{EV}$} \\
\hline 23.40 & $22.60 \%$ & $5.00 \%$ & $29.56 \%$ & 3.18 & 4.50 & 3.713 & 4.870 & 4.29 & \multicolumn{2}{|c|}{$C_{t}>\mathrm{EV}>V_{l}$} \\
\hline 21.00 & $28.38 \%$ & $5.00 \%$ & $59.11 \%$ & 3.25 & 3.02 & 3.974 & 5.454 & 4.71 & \multicolumn{2}{|c|}{$C_{t}<\mathrm{EV}$} \\
\hline 20.30 & $35.80 \%$ & $4.92 \%$ & $35.23 \%$ & 4.82 & 0.05 & 6.237 & 9.637 & 7.94 & \multicolumn{2}{|c|}{$C_{t}<\mathrm{EV}$} \\
\hline 16.48 & $17.72 \%$ & $4.92 \%$ & $17.17 \%$ & 7.16 & 0.18 & 8.031 & 9.901 & 8.97 & \multicolumn{2}{|c|}{$C_{t}<\mathrm{EV}$} \\
\hline
\end{tabular}

Data source: Wind.

(CSRC) and in face of delisting, because of its violation of securities laws and regulations according to Amarsoft's proclamation on February 15th, 2016.

In a word, the empirical study on separating equilibrium can verify the feasibility of Theorem 7 in China's IPO market. Besides, it also proves that investors can effectively distinguish the quality of information disclosure in the letter of intent on the basis of judge conditions in Theorem 7 to make a scientific purchase decision.

5.2. Empirical Study on Pooling Equilibrium. Based on the theoretical proof in Section 4.1, there are two judge conditions restraining the issuer and investor, respectively, to demonstrate that the only pooling equilibrium is the perfect Bayesian Nash equilibrium. Condition (1) $C_{h}<\mathrm{EV}$, restraining the investor, is the same as one of the conditions in Theorem 7; thus, the same empirical study method in Section 5.1 can be applied for it. Condition (2) $0<y<$ $S_{h}-S_{l}$, restraining the issuer, is empirically studied through two typical cases disclosed in the last three years, due to $y$ (the issuer's disguising cost per share for window dressing the letter of intent) unavailable as the private information except those cases of government disclosure.

5.2.1. Case 1: Sinovel (601588): Shanghai A Share in the Main Board. Sinovel's disclosure of false information, as a typical case, is studied empirically to verify the relationship between the disguising cost of the issuer and the bidding spread of offline investors in the main board of A share market, namely, the existence and effectiveness of condition (2) of Theorem 6 in the main board of China's A share market. As a typical sample of a falling-on-debut stock with high offering price, high price earnings ratio (PE), and overraising capital, the slump in Sinovel's price has been exceedingly rare not only in the main board but also in the whole A share market. The cause can be traced as severe distortion in information disclosure. According to the CSRC's investigation, Sinovel's case has been an unwonted and overwhelming case in China's capital market in the past five years, because of its violation of securities laws and regulations. This case study is expected to investigate the limitation of relevant domestic laws on regulating information disclosure and boost standardization of information disclosure in new issues.

As a leading enterprise in China's wind power industry, Sinovel collected bids of over 60 investors in the range of 80-90 (unit: yuan/share) after roadshows in December 2010. On January 5th, 2011, it confirmed its offering price at 90 and issued 105 million shares with 48.83 PE. On January 13th, Sinovel was issued in the main board of Shanghai's A share market, marking as the first high offering price and overraising stock of China's IPO market in the whole year. However, the stock fell on debut at the opening and closed at 81.37 in its first day of trading, 9.59\% lower than its offering price. Since then it had begun long-run underperformance. Its trading price has never surpassed its offering price and formed an L-shape trend so far. The highest trading price is 88.8 in its first year of issuing while its lowest price is 2.70 on February 29th, 2016, slumping by $97 \%$. It is clear that almost every investor purchasing IPO stocks of Sinovel has been trapped in the long run.

The CSRC announced the punishment on Sinovel's false information disclosure on November 20th, 2015. The CSRC imposed a fine of 0.6 million on the Sinovel enterprise, a total of 2.4 million on Sinovel's 14 persons in charge (PIC), 0.95 million on the auditor Reanda Certified Public Accountants, and a total of 0.2 million on Reanda's 2 PIC. Additionally, The CSRC confiscated business income of 0.95 million on Reanda, prohibited 7 PIC from entry into the securities market, and suspended sponsor qualification of essence security for three months.

According to the definition of the issuer in Section 2.2, the losses of Reanda Certified Public Accountants should be included in $y$. Thus, the issuer’s disguising cost stands at $¥ 5.1$ 
TABLE 3: Real-world parameters and results of empirical study in case 1.

\begin{tabular}{lcccccccccc}
\hline $\begin{array}{l}\text { Stock } \\
\text { name }\end{array}$ & Stock code & $T_{0}$ & $T_{1}$ & $T_{2}$ & $T_{1}-T_{0}$ (days) & $r_{1}(\%)$ & $T_{2}-T_{1}($ days $)$ & $r_{2}(\%)$ & $q(\%)$ \\
\hline Sinovel & 601588 & 2011.1 .5 & 2011.1 .10 & 2011.1 .13 & 6 & $5.58 \%$ & 2 & $5.58 \%$ & $10.34 \%$ \\
\hline$P_{0}$ & ROE $(\%)$ & $\rho(\%)$ & $\beta(\%)$ & $B V_{t}$ & $C_{t}$ & $V_{l}(N=1)$ & $V_{h}(N=3)$ & $\mathrm{EV}$ & $C_{t} \mathrm{VS} . \mathrm{EV}$ \\
\hline 90.00 & $82.20 \%$ & $5.58 \%$ & $35.20 \%$ & 3.57 & 9.39 & 6.161 & 14.854 & 10.51 & $C_{t}<\mathrm{EV}$ \\
\hline
\end{tabular}

Data source: Wind.

million for Sinovel $(601588)(=0.6+2.4+0.95+0.95+0.2)$. Namely, $y=5.1$ million yuan $/ 105$ million shares $=0.049$ yuan/share, while the investor's bidding spread $S_{h}-S_{l}=$ $90-80=10$ yuan/share. It is apparent that Sinovel's IPO conforms to $0<y<S_{h}-S_{l}$, condition (2) of Theorem 6 . Due to the low cost in disclosing false information, the issuer's equilibrium strategy must be attracting high bids $\left(S_{h}\right)$ from investors through disguising the letter of intent before IPO roadshow, despite relatively low intrinsic value of the IPO stock. With regard to condition (1) restraining the investor, the results in Table 3 can be acquired based on formulas (11) and (12).

It is clear that the opportunity cost of purchasing the IPO stock stays less than the expectation of the intrinsic value of the IPO stock in the forthcoming three years. Namely, $C_{t}<$ EV. Misguided by the false information disclosed in the letter of intent, offline investors might believe that the stock's intrinsic value remains higher; that is, $C_{t}=C_{h}$. Thus, Sinovel's IPO stock conforms to $C_{h}<\mathrm{EV}$, Condition (1) of Theorem 6. As a result, offline investors should adopt purchase $\left(A_{1}\right)$ as their equilibrium strategy after the IPO roadshow.

Consistent with Theorem 6, the issuer disclosed false information by window dressing the letter of intent to attract investors' relatively high bids $\left(S_{h}\right)$ in the IPO roadshow based on $0<y<S_{h}-S_{l}$, condition (2) of Theorem 6. On the other hand, misled by the false information disclosed, investors might purchase the IPO stock according to $C_{h}<$ EV, condition (1) of Theorem 6. When the IPO of Sinovel and other high-quality stocks are conducted at the same period, it is difficult to make effective distinguishment for the majority of investors. Therefore, they would like to purchase both types of stocks. As a consequence, the only pooling equilibrium $\left\{\left(S_{h}, S_{h}\right),\left(A_{1}, A_{1}\right), p\left(V_{l} \mid S_{l}\right)=1, p\left(V_{h} \mid S_{l}\right)=0\right\}$ exists as the perfect Bayesian Nash equilibrium when issuers and investors, respectively, satisfy the two conditions above.

5.2.2. Case 2: Wanfu Biotechnology (300268): Shenzhen A Share in the Growth Enterprise Market (GEM). Wanfu Biotechnology's disclosure of false information, as a typical case, is studied to verify the relationship between the disguising cost of the issuer and the bidding spread of offline investors in the GEM of A share market, namely, the effectiveness of condition (2) of Theorem 6 in the GEM. As the first IPO stock disguising information of the letter of intent in GEM, its disguising method is typically elusive and complicated. Correspondingly, the CSRC has imposed the most severe punishment in five years. This case study will help to scientifically control the degree of punishment on false information disclosure based on current laws and regulations so as to establish protection and compensation mechanism for investors.

Wanfu Biotechnology is mainly engaged in rice deepprocessing business. It has collected bids from over 80 institutional investors at the range of 9.2-32.3 (unit: yuan/share) after its IPO net roadshow on September 14th, 2011. On September 15th, 2011, it confirmed its offering price at 25 and issued 17 million shares with 33.78 PE. On September 27th, 2011, it was listed in the GEM of A share market. But in less than one year from issuing, the CSRC announced that Wanfu Biotechnology would be under investigation on September 18th, 2012. On October 22nd, 2013, the CSRC published administrative penalties on Wanfu Biotechnology and its IPO intermediaries:

(1) Imposing a fine of 0.3 million on the Wanfu Biotechnology enterprise and a total of 3.45 million on 20 persons in charge (PIC) and while banning the chairman of the board and the former CFO of the enterprise from securities market for life.

(2) Suspending the sponsor qualification of Ping An Securities for three months and imposing a fine of 76.65 million and establishing a special investor compensation fund of 300 million yuan to undertake investors' compensation liability together with Wanfu Biotechnology Company.

(3) Confiscating the business income of 1.38 million on the auditor Zhonglei Accounting Firm and imposing a fine of 2.76 million with its securities services business license revoked and warning and fining three accountants for a total of 0.25 million and banning two of them out of securities market for life.

(4) Confiscating the business income of 0.7 million on Boao Law Firm who offered legal services and imposing a fine of 1.4 million and warning the two PIC and fining them for 0.1 million, respectively.

As a consequence, Wanfu Biotechnology and its IPO intermediaries were fined 387.09 million totally. Based on the definition of the issuer in Section 2.2, it should be included in $y$; thus, $y=387.09$ million yuan $/ 17$ million share $=22.77$ yuan/share, while the investor's bidding spread $S_{h}-S_{l}=$ $32.30-9.20=23.10$ yuan/share. It is obvious that Wanfu Biotechnology falls in line with $0<y<S_{h}-S_{l}$, condition (2) of Theorem 6 . However, its span between $y$ and $S_{h}-S_{l}$ stays narrower than Sinovel's, as is the consequence of the CSRC's 
TABLE 4: Real-world parameters and results of empirical study in case 2.

\begin{tabular}{lcccccccccc}
\hline $\begin{array}{l}\text { Stock } \\
\text { name }\end{array}$ & Stock code & $T_{0}$ & $T_{1}$ & $T_{2}$ & $T_{1}-T_{0}$ (days) & $r_{1}(\%)$ & $T_{2}-T_{1}($ days $)$ & $r_{2}(\%)$ & $q(\%)$ \\
\hline $\begin{array}{l}\text { Wanfu } \\
\text { Biotech }\end{array}$ & 300268 & 2011.9 .15 & 2011.9 .20 & 2011.9 .27 & 6 & $5.58 \%$ & 6 & $5.58 \%$ & $4.72 \%$ \\
\hline$P_{0}$ & ROE $(\%)$ & $\rho(\%)$ & $\beta(\%)$ & $B V_{t}$ & $C_{t}$ & $V_{l}(N=1)$ & $V_{h}(N=3)$ & $\mathrm{EV}$ & $C_{t} \mathrm{VS} . \mathrm{EV}$ \\
\hline 25.00 & $17.53 \%$ & $5.58 \%$ & $0 \%$ & 4.92 & 1.204 & 5.477 & 6.693 & 6.08 & $C_{t}<\mathrm{EV}$ \\
\hline
\end{tabular}

Data source: Wind.

aggravating punishment. Due to underestimating the cost in disclosing false information, the issuer's equilibrium strategy must be attracting higher bids $\left(S_{h}\right)$ from investors through disguising the letter of intent before IPO roadshow, despite relatively low intrinsic value of the IPO stock. On basis of condition (1), the results in Table 4 are evaluated based on formulas (11) and (12).

It is clear that the opportunity cost of purchasing the IPO stock stays less than the expectation of the intrinsic value of the IPO stock in the forthcoming three years. Namely, $C_{t}<\mathrm{EV}$. Misguided by the false information disclosed in the letter of intent, offline investors might believe that the stock's intrinsic value remains higher; that is, $C_{t}=C_{h}$. Thus, Wanfu Biotechnology's IPO stock conforms to $C_{h}<\mathrm{EV}$, Condition (1) of Theorem 6. As a result, offline investors should adopt purchase $\left(A_{1}\right)$ as their equilibrium strategy after the IPO roadshow.

Consistent with Theorem 6, the issuer disclosed false information by window dressing the letter of intent to attract investors' relatively high bids $\left(S_{h}\right)$ in the IPO roadshow of Wanfu Biotechnology based on $0<y<S_{h}-S_{l}$, condition (2) of Theorem 6. On the other hand, misled by the false information disclosed, investors might purchase the IPO stock according to $C_{h}<\mathrm{EV}$, condition (1) of Theorem 6. When the IPO of Wanfu Biotechnology and other high-quality stocks are conducted at the same period, it is difficult to make effective distinguishment for the majority of investors. Therefore, they would like to purchase both types of stocks. As a consequence, the only pooling equilibrium $\left\{\left(S_{h}, S_{h}\right),\left(A_{1}, A_{1}\right), p\left(V_{l} \mid S_{l}\right)=1, p\left(V_{h} \mid S_{l}\right)=0\right\}$ exists as the perfect Bayesian Nash equilibrium when issuers and investors, respectively, satisfy the two conditions above.

In a word, the empirical study on pooling equilibrium can verify the effectiveness of Theorem 6 in China's IPO market. Meanwhile, it further proves that issuers can attract higher bids from investors through disguising the letter of intent in the roadshow of new issues.

\section{Conclusion and Enlightenment}

A signaling game model with the quality of letter of intent as the signal has been established in this paper in light of a dynamic game with incomplete information between the issuer and the investor during China's IPO net roadshow. Conclusions drawn through combining theoretical research with China's IPO market are listed as follows.

First and foremost, the issuer attempts to disguise the letter of intent. To avoid making the net roadshow into a mere formality, it is necessary to further clarify false statements and omission of information in legislation procedures. The level of stimulation and punishment should be enhanced according to the authenticity and completeness of information disclosure of the letter of intent. Apart from penalties, criminal responsibility should be further strengthened to increase disguising cost to lay a solid foundation of IPO registration around information disclosure.

In addition, the intrinsic values of IPO stocks and purchase opportunity cost are two major factors in the perfect Bayesian Nash equilibrium. When considering the letter of intent to be high-quality, the investor should decide to purchase IPO stocks, if the opportunity cost per share is less than the expectation on intrinsic value; on the contrary, the investor should reject purchase when the letter of intent is of low quality, as the opportunity cost per share outweighs the assessment of intrinsic value. Because IPO in China's A share market often operate in a "hot issue market," investors intend to overestimate the intrinsic value of IPO and underestimate purchase opportunity cost. It is this kind of irrational valuation that can explain the anomaly that investor also chooses to purchase even when participating in net roadshows of IPO stocks with a low intrinsic value.

Last but not the least, relevant laws including securities law should be revised and penalties on enterprises and persons in charge (PIC) violating laws and regulations on information disclosure should be reinforced. Apart from economic punishment, criminal responsibility should be further pushed on relevant PIC so as to uplift their comprehensive cost for disguising IPO information and the level of protection and compensation on investors.

\section{Competing Interests}

The authors declare that they have no competing interests.

\section{Acknowledgments}

This work was supported by the National Natural Science Foundation of China (NSFC) (Grant no. 71271070).

\section{References}

[1] Investor Relations Magazine, "Global roadshow report 2014," Working Paper, 2015.

[2] G. Clarke and L. W. Murray, "Advance in relationship marketing," Corporate Communications, vol. 5, no. 3, pp. 144-152, 2000. 
[3] B. Chen, "The current condition and development of IRM in the Chinese listed companies," Journal of Southwest Jiaotong University, vol. 6, no. 2, pp. 45-50, 2005.

[4] J. King, "QuanJing's net roadshow," China Internet Weekly, no. 7, p. 21, 2000

[5] L. J. Yi, "Road shows on the Internet: taking individual investors for a ride on the information highway," Duke Law Journal, vol. 52, no. 1, pp. 243-271, 2002.

[6] J. Hsu, W. Young, and H.-Y. Wang, "Pre-IPO acquirers' issuance cost and long-run performance: do their m\&a disclosures matter?" Journal of Business Finance and Accounting, vol. 39, no. 1-2, pp. 141-164, 2012.

[7] A. Leone, S. Rock, and M. Willenborg, "Disclosure of intended use of proceeds and underpricing in initial public offerings," Journal of Accounting Research, vol. 45, no. 1, pp. 111-153, 2007.

[8] S. P. Ferris, Q. Hao, and M.-Y. Liao, "The effect of issuer conservatism on ipo pricing and performance," Review of Finance, vol. 17, no. 3, pp. 993-1027, 2013.

[9] Z.-S. Chen, W. Hua, and G. Chen, "Study on the net roadshow and its governance mode," East China Economic Management, vol. 15, no. 5, pp. 94-96, 2001.

[10] W. Junqiao, Research on legal system of securities information internet disclosure regulation [Ph.D. thesis], Wuhan University, 2010.

[11] F. Allen and G. R. Faulhaber, "Signalling by underpricing in the IPO market," Journal of Financial Economics, vol. 23, no. 2, pp. 303-323, 1989.

[12] V. Fleischer, "The marketing consequences of IPOs," Betriebswirtschaftliche Forschung und Praxis, vol. 58, no. 5, pp. 457-467, 2006.

[13] Z. Zijian, "Accounting conservatism and underpricing in initial public offerings," in Proceedings of the 6th International Conference on Financial Risk and Corporate Finance Management, Dalian, China, 2014.

[14] X. Xianhu and L. Tian, "On off-balance-sheet intangible assets: based on the integration of financial and strategic perspectivesimultaneously analyzing intangible resources, intangible assets and intangible capital," Accounting Research, no. 4, pp. 3-9, 2014.

[15] E. M. Miller, "Risk, uncertainty, and divergence of opinion," The Journal of Finance, vol. 32, no. 4, pp. 1151-1168, 1977.

[16] A. Ljungqvist, V. Nanda, and R. Singh, "Hot markets, investor sentiment, and IPO pricing," Journal of Business, vol. 79, no. 4, pp. 1667-1702, 2006.

[17] D. O. Cook, R. Kieschnick, and R. A. Van Ness, "On the marketing of IPOs," Journal of Financial Economics, vol. 82, no. 1, pp. 35-61, 2006.

[18] F. Derrien, "IPO pricing in 'hot' market conditions: who leaves money on the table?" Journal of Finance, vol. 60, no. 1, pp. 487$521,2005$.

[19] H.-C. Chen, C.-J. Jhou, and H.-C. Yeh, "Signalling by underwriter retention rate in the IPO market," Applied Economics, vol. 39, no. 15, pp. 1973-1983, 2007.

[20] M. C. Bustamante, “The dynamics of going public," Review of Finance, vol. 16, no. 2, pp. 577-618, 2012.

[21] J. Birch, "Propositional content in signalling systems," Philosophical Studies, vol. 171, no. 3, pp. 493-512, 2014.

[22] L. Guanglei, Study on the Chinese formation mechanism of IPOs stock price [Ph.D. thesis], Tongji University, Shanghai, China, 2006.
[23] F. Kerins, K. Kutsuna, and R. Smith, "Why are IPOs underpriced? Evidence from Japan's hybrid auction-method offerings," Journal of Financial Economics, vol. 85, no. 3, pp. 637-666, 2007.

[24] G. Haixing, W. Difang, and W. Zuguang, "Do underwriters deserve trust: the evidence from china growth enterprise market," Nankai Business Review, vol. 14, no. 3, pp. 101-109, 2011.

[25] L. Shancun, L. Qianhui, S. Diauyu, and G. Yaqin, "The influence on the IPO price from the collusion of institutional investors," Management Review, vol. 25, no. 12, pp. 15-24, 2013.

[26] M. Zhong, A. Zeng, J. Huang, and K. Hong, "Project capital allocation combination equilibrium decision model based on behavioral option game," Discrete Dynamics in Nature and Society, vol. 2014, Article ID 803073, 11 pages, 2014.

[27] L. Xu, G. Kannan, X. Yang, J. Li, and X. Zhao, "Pricing and allotment in a sea-cargo supply chain with reference effect: a dynamic game approach," Discrete Dynamics in Nature and Society, vol. 2013, Article ID 162563, 10 pages, 2013.

[28] J. Leung and K. Menyah, "Issuer-oriented underpricing costs in initial public offers: evidence from Hong Kong," Journal of Corporate Finance, vol. 12, no. 5, pp. 897-905, 2006.

[29] M. Spence and R. Zeckhauser, "Insurance, information and individual action," American Economic Review, vol. 61, no. 2, pp. 380-386, 1971.

[30] J. Mirrlees, "The optimal structure of authority and incentives within an organization," Bell Journal of Economics, vol. 7, no. 1, pp. 105-131, 1976.

[31] L. Wu and X. Xia, "Positive feedback traders, the offer price constraint and IPO pricing," in Proceedings of the 6th International Conference on Service Systems and Service Management (ICSSSM '09), pp. 546-551, IEEE, Xiamen, China, June 2009.

[32] Z. Weiying, Game Theory and Information Economics, Truth \& Wisdom Press, Shanghai, China, 1996.

[33] D. Du, "The selection of IPO valuation model in China stock market," Accounting Research, no. 7, pp. 82-85, 2013.

[34] L. Huangsong, "The theory of the stock intrinsic value and the bubble of China's stock market," Economic Research Journal, no. 2, pp. 45-52, 2005.

[35] S. H. Chan, K. Wang, and J. Yang, "IPO pricing strategies with deadweight and search costs," Journal of Real Estate Research, vol. 31, no. 4, pp. 481-542, 2009.

[36] PBC School of Finance of Tsinghua University, "Global fintech business model report 2015," in Proceedings of the 2nd World Internet Conference, Wuzhen, China, 2015.

[37] China Securities Regulatory Commission, The 28th Information Disclosure Content and Format Standards for Listed Companies (The Revised Version), China Securities Regulatory Commission's Proclamation, Beijing, China, 2014. 


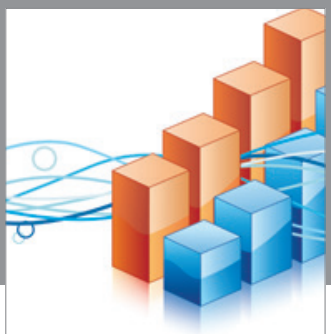

Advances in

Operations Research

vatem alat4

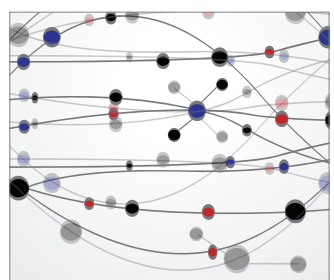

\section{The Scientific} World Journal
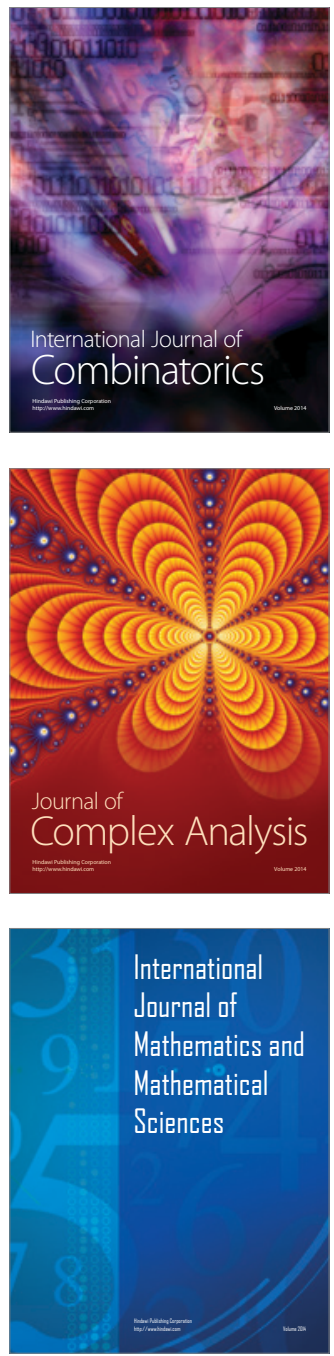
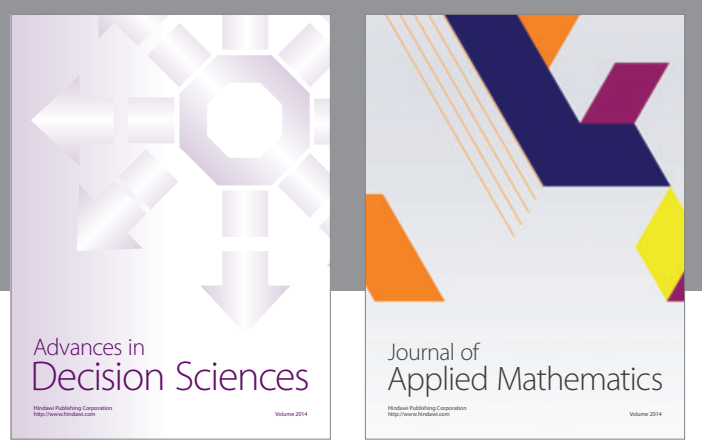

Algebra

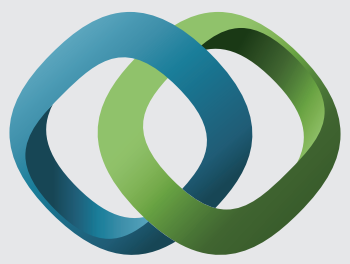

\section{Hindawi}

Submit your manuscripts at

http://www.hindawi.com
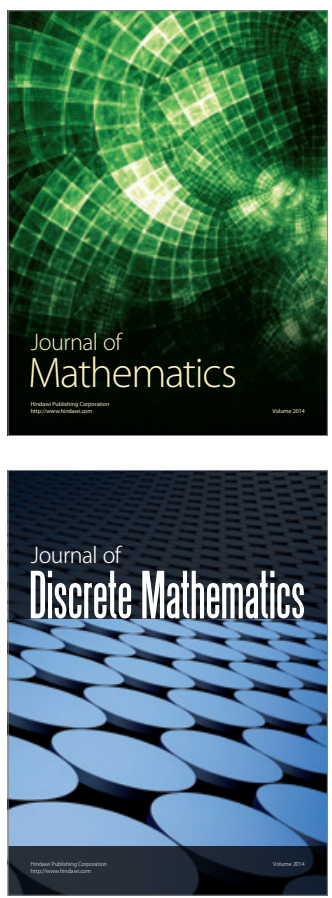

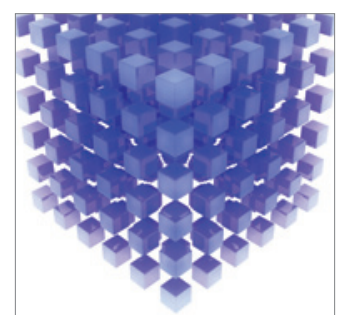

Mathematical Problems in Engineering
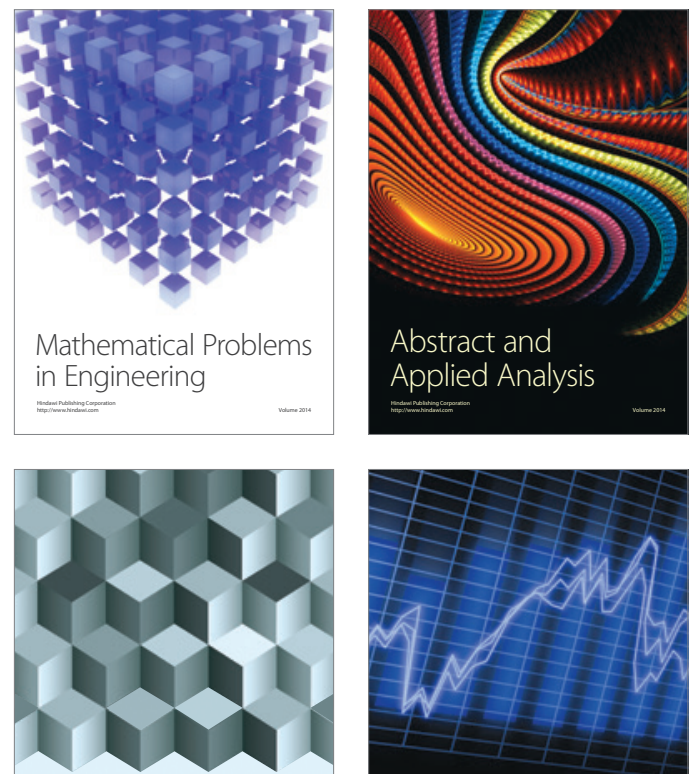

Journal of

Function Spaces

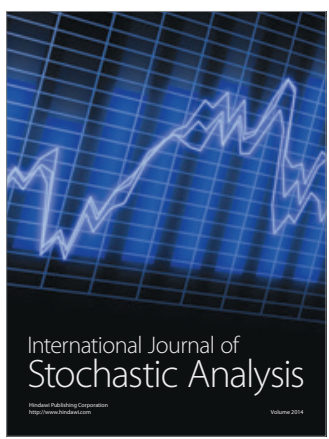

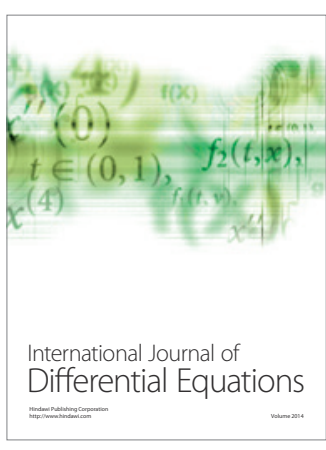
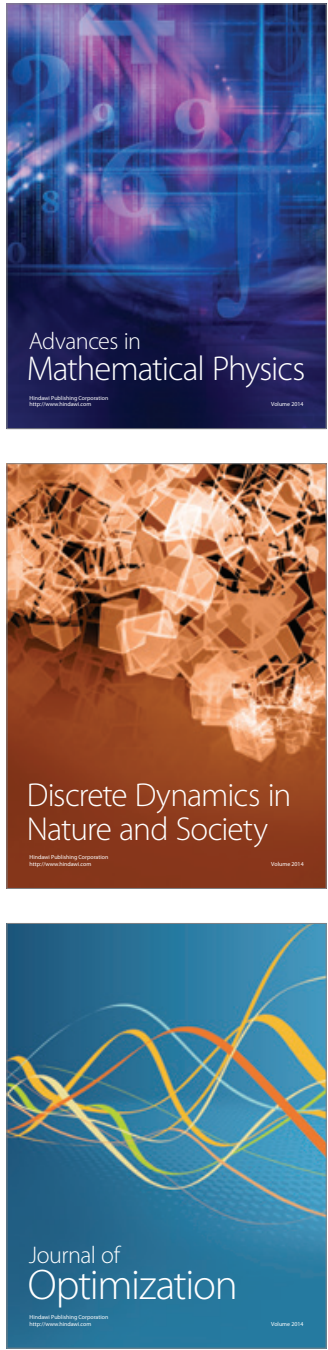